\title{
HISTÓRICO E PERSPECTIVA DA SITUAÇÃO SANITÁRIA DA FEBRE AFTOSA no estado de São Paulo
}

\section{History and perspective of Sanitary Status of Foot-and- Mouth Disease in São Paulo state}

\author{
Hugo Leonardo Riani Costa ${ }^{10}$, Adriano Macedo Debiazzi $^{1}$, Maria Carolina Guido ${ }^{2}$, \\ Luciano LaGatta ${ }^{1}$ \\ *Autor Correspondente: Hugo Leonardo Riani Costa. Coordenadoria de Defesa Agropecuária, \\ Avenida Brasil, 2340, Jardim Chapadão, Campinas, SP, Brasil. CEP 13070-178.
}

Como citar: COSTA, Hugo Leonardo Riani et al. Histórico e perspectiva da situação sanitária da febre aftosa no estado de São Paulo. Revista de Educação Continuada em Medicina Veterinária e Zootecnia do CRMV-SP, São Paulo, v.19, n.1, 2021, e38037. Doi 10.36440/recmvz.v19i1.e38037.

Cite as: COSTA, Hugo Leonardo Riani et al. History and perspective of Sanitary Status of Foot-and-Mouth Disease in São Paulo state. Journal of Continuing Education in Veterinary Medicine and Animal Science of CRMV-SP, São Paulo, v.19, n.1, 2021, e38037. Doi 10.36440/recmvz.v19i1e38037.

\section{Resumo}

A febre aftosa é uma doença infecciosa aguda, causada por vírus do gênero Aphthovirus, da família Picornaviridae. Apresenta grande impacto sobre a sanidade dos animais e, em função da elevada capacidade de difusão, é considerada a doença com maior interferência no comércio internacional de carnes. Em virtude de suas consequências diretas e indiretas, o combate à febre aftosa é uma das maiores preocupações de todos os envolvidos com a pecuária nacional, desde o início do século passado. Em decorrência dos grandes esforços realizados, o Brasil passou a ser reconhecido como país livre de febre aftosa e, atualmente, busca galgar um novo patamar, com a suspensão da vacinação em todo seu território. A participação dos médicos-veterinários foi fundamental neste processo e continuará sendo essencial nos desafios futuros.

Palavras-chave: Febre Aftosa. Pecuária. Sanidade Animal.

\section{Abstract}

Foot-and-mouth disease (FMD) is an acute infectious disease caused by a virus of the genus Aphthovirus, family Picornaviridae. FMD has a great impact on the health of animals and, due to high diffusion capacity, it is considered the disease with the greatest interference in the international meat trade. Due to its direct and indirect consequences, the combat against FMD has been a major concern for all those involved with national livestock since the beginning of the last century. As a result of the great efforts, Brazil started to be recognized as an FMD free country and, currently, it seeks to reach a

1 Médico-veterinário, Grupo de Defesa Sanitária Animal, Coordenadoria de Defesa Agropecuária, Secretaria de Agricultura e Abastecimento do Estado de São Paulo, Campinas, SP, Brasil

2 Médica-veterinária, Escritório de Defesa Agropecuária de São Paulo, Coordenadoria de Defesa Agropecuária, Secretaria de Agricultura e Abastecimento do Estado de São Paulo, São Paulo, SP, Brasil 
new level, with the suspension of vaccination throughout its territory. The participation of veterinarians was very important in this process and will continue to be essential in future challenges.

Keywords: Foot and Mouth Disease (FMD). Livestock. Animal Health.

\section{Introdução}

A febre aftosa é uma das doenças infecciosas mais contagiosas que acometem os animais de produção, levando à formação de vesículas que evoluem para erosões na boca, narinas, focinho, patas e tetas. Adicionalmente, os animais apresentam elevação na temperatura corporal, apatia e diminuição da ingestão de água e alimentos. Há grande diminuição da capacidade produtiva dos animais acometidos, mesmo aqueles que se recuperam clinicamente.

A doença possui grande importância econômica. Os impactos decorrentes de focos envolvem prejuízos diretos e indiretos, e podem compreender desde a redução nos preços até a suspensão das exportações, causando prejuízos econômicos a todos os segmentos da cadeia produtiva.

Em virtude da grande importância da doença, tanto para a saúde animal quanto para o comércio de produtos agropecuários, o combate à febre aftosa contribuiu para a criação do Ministério da Agricultura, em 1909. O Decreto Federal no 24.548, de 03/07/1934, apresentava restrições e orientações referentes à ocorrência da febre aftosa. Em 1950, foram estabelecidas as normas para prevenção da doença e, na década de 1960, houve a institucionalização da campanha de combate à febre aftosa. Nos anos 1990, houve a implantação da política de erradicação, com regionalização das ações e meta de país livre, objetivo alcançado em 2018.

Após décadas de grandes esforços por parte de produtores rurais, médicos-veterinários, instituições de ensino e pesquisa, indústria farmacêutica, setor de alimentos de origem animal e do Serviço Veterinário Oficial (governos estaduais e federal), atualmente, o Brasil encontra-se em uma fase de transição para melhoria do status sanitário, tendo como um dos objetivos a retirada da vacinação em todo o território nacional.

A participação dos médicos-veterinários (autônomos, funcionários da iniciativa privada e servidores públicos) foi de fundamental importância para as conquistas obtidas até o presente, e continuará sendo extremamente necessária no cenário futuro.

\section{Objetivos}

Os objetivos deste artigo técnico são:

- Apresentar uma breve revisão sobre a febre aftosa.

- Ressaltar os impactos da doença sobre o comércio de produtos agropecuários.

- Apresentar o histórico das principais medidas adotadas no Brasil e no estado de São Paulo para o controle e erradicação da doença.

- Discutir a situação sanitária atual e os próximos desafios.

- Destacar a importância da vigilância veterinária como medida indispensável para garantir a detecção precoce de possível reingresso do vírus.

\section{Felore aftosa}

A febre aftosa é uma enfermidade infectocontagiosa vesicular, causada por um pequeno vírus de RNA, icosaédrico e não envelopado, pertencente à família Picornaviridae, do gênero Aphthovirus, 
que apresenta sete sorotipos ( $A, 0, C, S A T 1, S A T 2$, SAT3 e ASIA1), sendo que os três primeiros já foram diagnosticados na América do Sul (MELO et al., 2020).

É uma doença de notificação obrigatória que acomete animais biungulados, como bovinos, bubalinos, suídeos e pequenos ruminantes, que implica em importantes perdas econômicas e é considerada uma das doenças de rebanho mais contagiosas. Por tais características, trata-se de uma importante barreira sanitária no comércio internacional de produtos de origem animal (GARCIA et al., 2015). É caracterizada por alta morbidade, podendo causar mortalidade em animais jovens e perdas produtivas significativas em adultos (MELO et al., 2020).

Clinicamente, a febre aftosa caracteriza-se por febre e vesículas, que evoluem para erosões na boca, narinas, focinho, patas e tetas. Os sinais clínicos típicos incluem depressão, anorexia, salivação excessiva, descarga nasal serosa, diminuição da produção de leite, claudicação e resistência a movimentar-se. Em bovinos, lesões orais são comuns com vesículas na língua, pulvino dental, gengivas, palato mole, narinas e focinho. Lesões de casco são encontradas na área da banda coronária e do espaço interdigital. Em suínos, as lesões de casco são geralmente severas com vesículas na banda coronária e espaço interdigital. Vesículas também podem ser detectadas no focinho. Ovinos e caprinos, quando apresentam sinais de febre, lesões orais e claudicação, são muito brandos (BRASIL, 2009).

\section{Impacto econômico da febre aftosa}

A febre aftosa é uma barreira sanitária no comércio internacional e implica elevados investimentos para seu controle e graves prejuízos em casos de surto (GARCIA et al., 2015). A ocorrência da doença afeta diretamente as exportações de carne e derivados, pois as barreiras sanitárias e fitossanitárias, principalmente por parte dos países europeus e Estados Unidos, levam a embargos do produto, tendo em conta a segurança e a qualidade dos produtos agroalimentares, fazendo com que outros países sigam o mesmo comportamento (SILVA, 2016).

Os impactos não se limitam aos estados que registram focos da doença. Em decorrência dos mais recentes focos registrados no Brasil (Mato Grosso do Sul e Paraná, entre 2005 e 2006), o estado de São Paulo perdeu US\$ 1 bilhão com exportações em 2006, mesmo sem registrar um único caso de febre aftosa (GONÇALVES; GHOBRIL, 2007).

\section{Evolução do processo de erradicação da febre aftosa no Brasil e no estado de São Paulo}

A doença foi detectada, pela primeira vez, na Itália, em 1514. No Brasil, o primeiro registro ocorreu, em 1895, coincidindo com a importação sistemática de reprodutores bovinos de raças europeias (LYRA; SILVA, 2004; SILVA, 2016).

A ocorrência da doença contribuiu para a criação, em 1909, do Ministério da Agricultura (LYRA; SILVA, 2004). Em 1934, o Ministério da Agricultura investiu na prevenção com ações contra a aftosa, publicando o Regulamento do Serviço de Defesa Sanitária Animal. Entretanto, as instruções específicas para o controle da doença, que incluíam a vacinação, foram definidas em 1950 (SILVA, 2016). A institucionalização do primeiro programa de combate à doença ocorreu na década de 1960 (LYRA, 2003). No estado de São Paulo, a "Campanha de Combate à febre aftosa" foi instituída pelo Decreto Lei n 49, de 25/04/1969 (SILVA, 2016).

Em 1992, quando nenhum dos estados brasileiros era considerado livre de febre aftosa, as estratégias foram reformuladas visando à erradicação da doença, com o envolvimento do setor privado (pecuaristas, frigoríficos, laboratórios produtores de vacinas), e dos governos estaduais e 
federal. Desde então, o Programa Nacional de Erradicação da febre aftosa evoluiu consideravelmente, com a implantação progressiva de zonas livres (MÜLLER et al., 2007; BRASIL, 2017).

0 último foco de febre aftosa registrado no estado de São Paulo ocorreu em março de 1996. 0 estado é reconhecido pela OIE como livre de febre aftosa com vacinação desde 2000 . Em outubro de 2005, esse reconhecimento foi suspenso em virtude da reintrodução do vírus da febre aftosa nos estados do Mato Grosso do Sul e Paraná (SILVA, 2016).

Em maio de 2008, houve restituição do reconhecimento de zona livre de febre aftosa para os estados de São Paulo, Bahia, Distrito Federal, Espírito Santo, Goiás, Mato Grosso, Minas Gerais, Paraná, Rio de Janeiro, Sergipe e Tocantins (OIE, 2008).

Desde 2018, todo o território nacional é reconhecido como área livre de febre aftosa, status compartilhado com grande parte da América do Sul, conforme mapa abaixo, extraído do site da OIE (https://www.oie.int/en/animal-health-in-the-world/official-disease-status/fmd/en-fmd-carte/).

Figura 1: Situação sanitária para febre aftosa na América do Sul

\section{SOUTH AMERICA: OIE Members' official FMD status map}

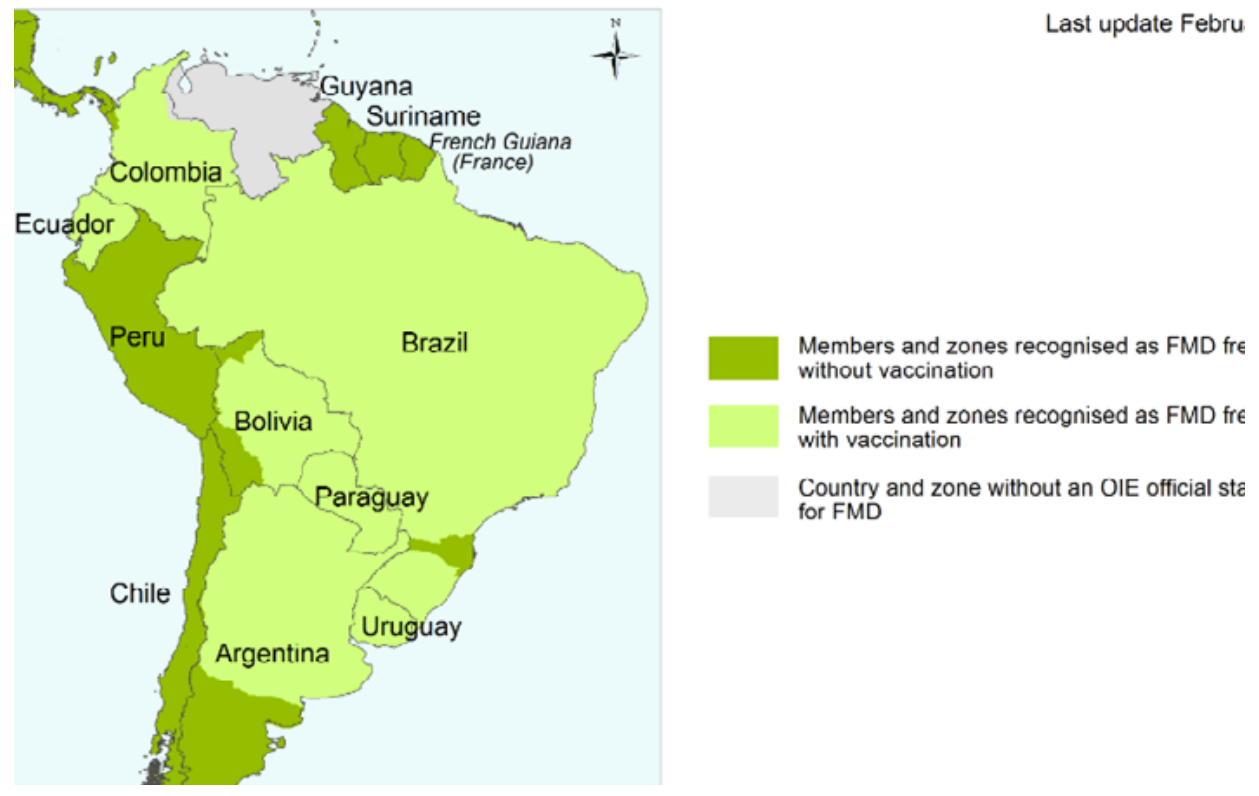

Fonte: OIE, 2020.

Entre as medidas adotadas no estado de São Paulo que contribuem para o reconhecimento internacional como área livre de febre aftosa, podemos ressaltar:

- Acompanhamento de vacinações durante as etapas de vacinação compulsória (vacinações assistidas e vacinações fiscalizadas);

- Atendimento à notificação de suspeitas;

- Fiscalizações do trânsito de animais e produtos de origem animal;

- Inspeção oficial (federal, estadual e municipal) em abatedouros das espécies susceptíveis;

- Estudos epidemiológicos - avaliação de circulação viral e de eficiência da vacinação;

- Vigilância ativa;

- Vigilância realizada pelos médicos-veterinários responsáveis técnicos em eventos de concentração de animais (rodeios, exposições, leilões). 
A tabela abaixo apresenta as quantidades das principais atividades realizadas nos últimos anos:

Tabela 1: Principais atividades realizadas para a manutenção do reconhecimento sanitário. Dados extraídos dos Sistemas Informatizados "Gedave" e "Relatório de Atividades", da Coordenadoria de Defesa Agropecuária do Estado de São Paulo

\begin{tabular}{|l|c|c|c|c|c|}
\hline & $\mathbf{2 0 1 5}$ & $\mathbf{2 0 1 6}$ & $\mathbf{2 0 1 7}$ & $\mathbf{2 0 1 8}$ & $\mathbf{2 0 1 9}$ \\
\hline Vacinações acompanhadas & 2.395 & 2.111 & 1.937 & 1.764 & 2.026 \\
\hline Atendimento a suspeitas & 2 & 2 & 2 & 14 & 15 \\
\hline Fiscalizações do trânsito & 476 & 542 & 348 & 294 & 396 \\
\hline Vigilância ativa & 1.520 & 1.342 & 1.497 & 1.396 & 1.614 \\
\hline Eventos de concentração & 2.873 & 2.937 & 2.731 & 2.918 & 2.442 \\
\hline
\end{tabular}

Fonte: Coordenadoria de Defesa Agropecuária do Estado de São Paulo, 2019.

Com relação aos últimos estudos epidemiológicos realizados, em conjunto com o Ministério da Agricultura, Pecuária e Abastecimento (Mapa), em 2014, foi realizado inquérito sorológico que comprovou a ausência de circulação viral no Estado de São Paulo, e estudo de eficiência da vacinação que mostrou índices satisfatórios de imunidade dos animais. Maiores informações sobre os estudos estão disponíveis no sítio eletrônico do Mapa (agricultura.gov.br/febre-aftosa). No mês de novembro de 2020, foram colhidas amostras para novo estudo para avaliação da eficiência da vacinação contra a febre aftosa.

\section{Próximos passos: Plano Estratégico 2017-2026}

O Plano Estratégico do Programa Nacional de Erradicação e Prevenção da Febre Aftosa (Pnefa/ Mapa) tem como objetivo principal criar e manter condições sustentáveis para garantir o status de país livre da febre aftosa e ampliar as zonas livres sem vacinação, protegendo o patrimônio pecuário nacional e gerando o máximo de benefícios aos atores envolvidos e à sociedade brasileira (BRASIL, 2017).

Um dos seus objetivos é a suspensão gradual da vacinação contra a febre aftosa, em todo o território brasileiro, que implica na adoção de diversas ações a serem desenvolvidas em âmbito municipal, estadual e nacional, com o envolvimento do Serviço Veterinário Oficial (SVO), setor privado, produtores rurais e agentes políticos (BRASIL, 2019). Em virtude dos impactos decorrentes dos períodos da pandemia e pós-pandemia do novo coronavírus (Covid-19), a suspensão da vacinação contra a febre aftosa, prevista para ocorrer a partir de maio do próximo ano, fica interrompida nos estados que compõem os Blocos II, III e IV do Plano Estratégico, incluindo o estado de São Paulo. Uma nova avaliação será realizada no primeiro semestre de 2021 (BRASIL, 2020).

\section{Importância dos médicos-veterinários para os próximos desafios}

Com a perspectiva da retirada da vacinação contra a febre aftosa, a vigilância veterinária para doenças vesiculares passa a ter um papel ainda mais relevante para a manutenção do status sanitário e para que o possível reingresso da doença em nosso estado seja detectado o mais precocemente 
possível, diminuindo os impactos desse possível reingresso e permitindo que o retorno à condição de livre seja realizado o mais breve possível.

Os médicos-veterinários que prestam atendimento às espécies susceptíveis têm contato direto com animais que podem apresentar alterações clínicas compatíveis com síndrome vesicular (conjunto de doenças com apresentação clínica semelhante à febre aftosa), e devem estar preparados para reconhecer os principais sinais clínicos, notificando ao Serviço Veterinário Oficial a detecção de casos suspeitos.

As notificações podem ser realizadas através do Sistema Brasileiro de Vigilância e Emergências Veterinárias/Sisbravet (http://www.agricultura.gov.br/notificacao) ou junto às Unidades da Defesa Agropecuária do Estado de São Paulo (relação disponível em https://www.defesa.agricultura.sp.gov. br/enderecos).

Nos últimos anos, diversas ocorrências foram reportadas ao Serviço Veterinário Oficial, com importante participação dos médicos-veterinários. Em todos os casos, foram realizadas investigações por médicos-veterinários da defesa agropecuária, auxiliados por colegas das carreiras de apoio agropecuário. Quando são verificadas lesões sugestivas de síndrome vesicular, ocorre interdição da movimentação de animais e colheita de material para o diagnóstico definitivo, além da investigação nas propriedades que possuem vínculo epidemiológico. Nos casos atendidos nos últimos anos, foi possível descartar a presença do vírus da febre aftosa, sendo obtidos alguns diagnósticos conclusivos como: varíola bovina (pelo vírus Vaccinia), pseudovaríola (causada pelo vírus Pseudocowpox) e doença vesicular em suínos (decorrente da infecção por Senecavirus).

Com a evolução na situação sanitária do estado de São Paulo, a notificação precoce das suspeitas de febre aftosa e demais doenças de peculiar interesse torna-se cada vez mais importante, e o engajamento dos médicos-veterinários privados é imprescindível. Desse modo, a capacitação destes profissionais deve ser alvo de esforços por parte do Serviço Veterinário Oficial (CDA e Mapa), instituições de ensino em Medicina Veterinária e conselhos de classe (CRMVs e CFMV).

Figura 2: Lesão com perda de epitélio em ápice/corpo da língua de búfalo com pseudovaríola no município de Barra do Turvo/SP em 17/06/2016

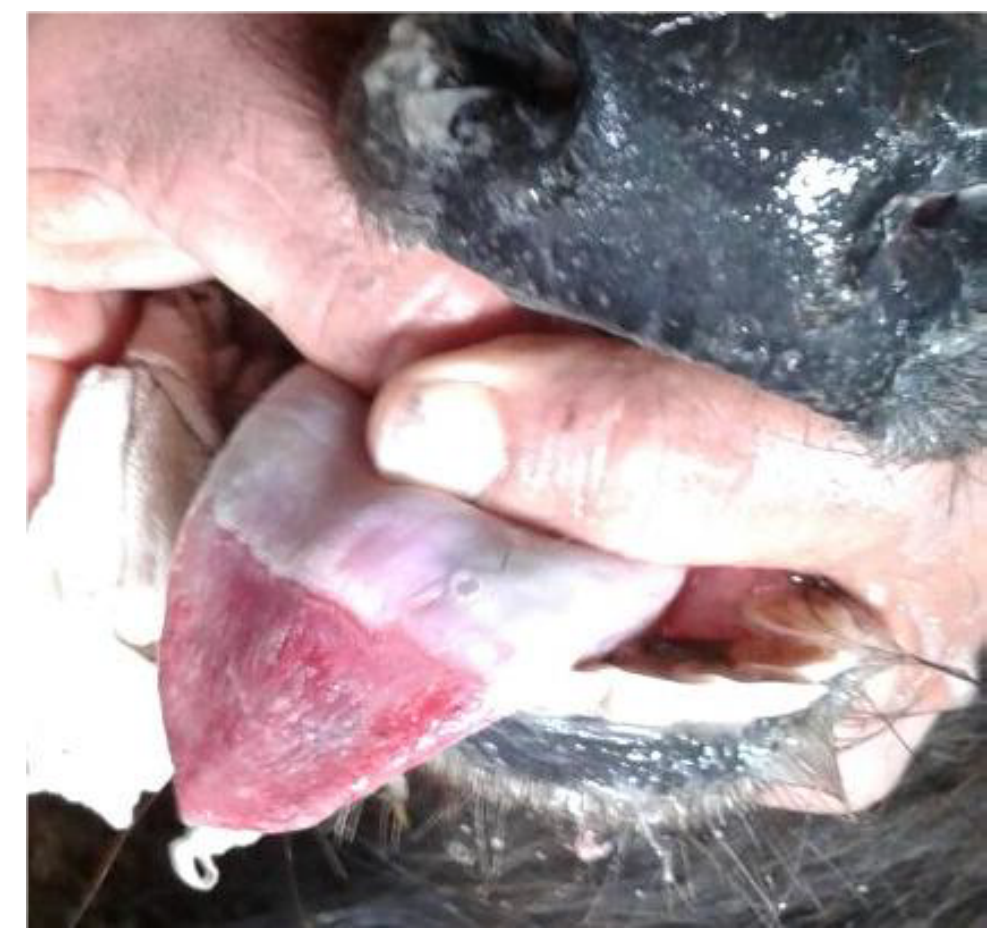

T Fonte: Escritório de Defesa Agropecuária de Registro (EDA), 2016. 
Figuras 3 e 4: Suínos com infecção por Senecavirus apresentando lesões compatíveis com síndrome vesicular em ápice nasal (plano rostral), no município de Ipuã/SP em 29/10/2018
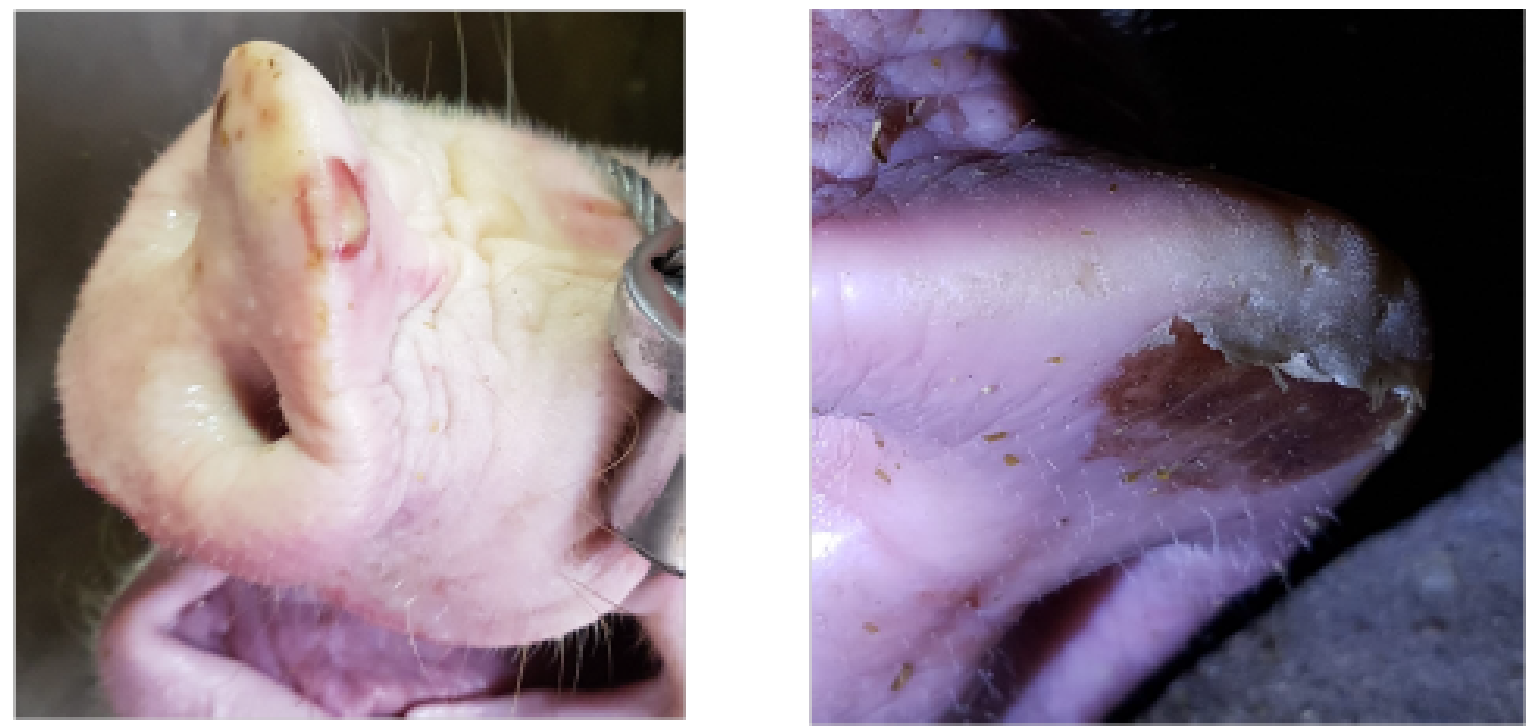

T Fonte: Escritório de Defesa Agropecuária de Franca (EDA), 2018.

\section{Conclusão}

A febre aftosa é uma doença com grande importância tanto para a saúde animal quanto para o comércio de produtos agropecuários. Por este motivo, estratégias de combate vêm sendo adotadas há muito tempo. Em decorrência dos grandes esforços realizados por todos os envolvidos, o Brasil alcançou o reconhecimento de país livre de febre aftosa e, atualmente, busca melhorar seu status sanitário, com a suspensão da vacinação em todo seu território. Com essa nova situação sanitária, a notificação de suspeitas de doenças vesiculares, que é obrigatória para todo cidadão, passará a ter importância ainda maior. A participação dos médicos-veterinários foi de fundamental importância para as conquistas obtidas até o presente, e será essencial nos desafios futuros, especialmente na vigilância das doenças vesiculares. \&

\section{Referências}

BRASIL. Ministério da Agricultura, Pecuária e Abastecimento. Secretaria de Defesa Agropecuária. Plano de ação para febre aftosa. Brasília, DF: Ministério da Agricultura, 2009.

BRASIL. Ministério da Agricultura, Pecuária e Abastecimento. Secretaria de Defesa Agropecuária. Programa Nacional de Erradicação e Prevenção da Febre Aftosa (PNEFA) / Plano Estratégico 2017 - 2026. Versão 1.0. Brasília, DF: Ministério da Agricultura, 2017.

BRASIL. Ministério da Agricultura, Pecuária e Abastecimento. Secretaria de Defesa Agropecuária. Programa Nacional de Erradicação e Prevenção da Febre Aftosa - PNEFA / Plano Estratégico - 2017 - 2026. Atualização 2019. Brasília, DF: Ministério da Agricultura, 2017.

BRASIL. Ministério da Agricultura, Pecuária e Abastecimento. Mapa faz reuniões virtuais sobre Plano Estratégico de Prevenção e Erradicação da Febre Aftosa. Brasília, DF: Ministério da Agricultura, 2020. Disponível em: https://www.gov.br/agricultura/pt-br/assuntos/noticias/mapa-faz-reunioes-virtuaissobre-plano-estrategico-de-prevencao-e-erradicacao-da-febre-aftosa. Acesso em: 06 out. 2020. 
GARCIA, D. C. C. et al. Impactos do surto de febre aftosa de 2005 sobre as exportações de carne bovina brasileira. Ciência Animal Brasileira, Goiânia, v.16, n. 4, p.525-537, 2015. DOI: https://doi. org/10.1590/1089-6891v16i426158.

GONÇALVES, J. S.; GHOBRIL, C.N. Febre Aftosa em estados vizinhos: SP perde nas exportações por falha alheia. Análises e Indicadores do Agronegócio, São Paulo, v. 2, n. 3, mar. 2007. Disponível em: http:// www.iea.sp.gov.br/out/verTexto.php?codTexto=8791. Acesso em: 13 de abr. 2020.

LYRA, T. M. P. A febre aftosa no Brasil: evolução e determinantes das políticas públicas de controle e erradicação, 1950-2002. 130f. Tese (Doutorado em Ciência Animal) - Escola de Veterinária, Universidade Federal de Minas Gerais, Belo Horizonte, 2003.

LYRA, T. M.P.; SILVA, J. A. A febre aftosa no Brasil, 1960-2002. Arquivo Brasileiro de Medicina Veterinária e Zootecnia. Belo Horizonte, v.56, n.5, p.565-576, out. 2004. DOI: https://doi.org/10.1590/5010209352004000500001.

MELO, W. G. G. et al. Febre Aftosa: Revisão de Literatura. Revista Científica Eletrônica de Medicina Veterinária, ano XVII, n.34, jan. 2020. Disponível em: http://faef.revista.inf.br/imagens_arquivos/ arquivos destaque/JiyE2q09Sli3075 2020-2-6-17-51-1.pdf. Acesso em: 14 de abr. 2020.

MÜLLER, C. A. S.; MATTOS, L. B.; LIMA, J. E. Determinantes da Erradicação da Febre Aftosa no Brasil. Organizações Rurais \& Agroindustriais, Lavras, v. 9, n. 1, p. 89-97, 2007.

OIE. Resolutions adopted by the Internacional Committee of the OIE during its 76th General Session 25-30 May 2008: Resolution no. XVIII - Recognition of the Foot and Mouth Disease Status of Members. Bulletin, Paris, v. 2008, n. 4, p. 38-39, 2008. Disponível em: https://www.oie.int/fileadmin/Home/ eng/Publications \%26 Documentation/docs/pdf/bulletin/Bull_2008-4-ENG.pdf. Acesso: 06 de out. 2020.

SILVA, R. O. P. Situação da Febre Aftosa no Brasil. Análises e Indicadores do Agronegócio, São Paulo, v. 11, n. 6, jun. 2016. 